\title{
On the Teaching Reform of Fieldwork in Human Geography
}

\author{
Wenshi LI \\ School of Resource and Environmental Science \\ Quanzhou Normal University \\ Quanzhou Fujian 362000, China
}

\author{
Zirong LI \\ School of Resource and Environmental Science \\ Quanzhou Normal University \\ Quanzhou Fujian 362000, China
}

\begin{abstract}
At present, there are some problems in the human geography fieldwork in normal universities, such as insufficient awareness of fieldwork, poor selection of location and contents, inadequate application of methodology, and few teaching practice-related contents in the theoretical courses. In light of these problems, this paper attempts to explore the improvement of the effect of human geography fieldwork from the perspective of increased awareness, proper choice of location and contents, comprehensive use of multiple methods and techniques, and sound application of the results of fieldwork in teaching theoretical courses. Furthermore, in order to improve the quality of ge ography field work, efforts should also be made in conducting the international fieldwork and effectively integrating the physical geography fieldwork with human geography fieldwork.
\end{abstract}

Keywords-fieldwork course; teaching reform; digital equipment; teaching mode; human geography; Shanghai; Quanzhou

\section{INTRODUCTION}

As a major field of geography, human geography is concerned with human-environment relations and interactions, i.e. the place, space and environments that are both the condition and the result of human activities[1]. Fieldwork is perceived to be an essential part of studying human geography. The human geography fieldwork of undergraduate geography majors must be paid attention to in order to increase its efficiency.

Geography has had a strong bond with fieldwork since its origination. Fieldwork has long been perceived to lie at the heart of geography. Both human and physical geographers take proficiency in field techniques as a worthy pursuit. Accordingly, fieldwork has been taken as an essential component of undergraduate in geography for "fieldwork gives opportunities for learning, which cannot replaced by the classroom teaching"[2]. And taking fieldwork as one of the important parts of the curricula, even as core curricula is beyond doubt.

The paper begins with problems of the human geography fieldwork. And it continues with the measure to improve the quality of human geography fieldwork, including increased awareness of the importance domains, integration of multitechnology, and extension of the fieldwork. It concludes with final thoughts on the improvement of the efficiency of fieldwork.

\footnotetext{
This work is financed by the human geography undergraduate teaching engineering and teaching reform project (Academic administration, Quanzhou normal university)
}

\section{Problems in the Human GeOGRAPHy FieldWork}

The inadequate teaching funds and limited class periods of fieldwork courses, along with the fact that different sub discipline courses of human geography are taught by many teachers who often fail to lead in the field trip together give rise to the problems in human geography fieldwork. Firstly, the importance of human geography fieldwork is undervalued and considered as sight-seeing rather than an opportunity to enhance the theoretical knowledge, skill training and capability cultivation. Secondly, the choice of location and program of field work is quite random. Some universities may pick up untypical locations for human geography field work because of their proximity to the universities. Some may even substitute video-watching for field work. Thirdly, the methodologies of field work are too simple with insufficient application of technological means. Fourthly, the connection between field work and theoretical teaching in classroom is far from satisfactory and the fruits of the former are not extensively and intensively applied to the latter. Thus the human geography field work skills required by teachers of primary schools and middle schools cannot be comprehensively trained in this way. This calls for more attention to the status quo by educators of geography in normal universities to enhance the efficiency of human geography field work.

\section{QuALity IMPROVEMENT OF HUMAN GEOGRAPHY FIELDWORK}

\section{A. Awareness of the importance of fieldwork}

In the era of globalization, it is necessary for higher education to be adjusted to the labor market demands and needs of a modern society[3]. There is a need for better field work skills and geographical pedagogy for teachers in primary and junior schools. As a consequence, the quality of fieldwork as a key component of the geographical education in normal universities should be highlighted.

Learning on and from fieldwork isn't only an extension or improvement of classroom teaching, but also a valuable supplement and addition to classroom instruction, as well as an excellent way to prepare students for future learning[4]. Rather than passively absorbing knowledge and theories in classroom, students participate actively in the fieldwork. By observation, description, and categorization the landscape out 
of the classroom, geographic concepts and theories are understood better and the skills include, but are not limited to, collaboration, leadership, and team building are cultivated gradually. The effect of learning in an outdoor setting proves to be better than that of classroom learning, judging from the appropriateness of students' application of geographical concepts to their acquisition of knowledge. In doing so, students get better understanding of the landscape and the human-environment linkages in it. Ideas emerging during the fieldwork become important source of the students' degree thesis.

\section{B. Choice of typical and representative domains for fieldwork teaching}

Human geography is such a broad field of study that it is nearly impossible to categorize the multitude of topics it covers. Its primary field of study focus around the core fields of population, economic, development, culture, settlement, and political. Typical and representative domains for fieldwork teaching are necessary to reach the required standard. Through the selected domains, students can have a deeper understanding of the nature of human geography and realize its application function and enhance their interests. Domains used in our field work teaching in Shanghai and Quanzhou include the following aspects: urbanization and urban-rural planning, land utilization in urban and rural areas, landscape architecture and users' preferences and perceptions, transportation system in urban and rural areas, culture landscape, population mobility and globalization, urban commercial spatial structure.

- Urbanization and urban planning: As a demographic, economic, and sociocultural phenomena, urbanization can be observed, measured, analyzed, and understood at many geographic scales[5]. The investigation and analysis on the urbanization should be conducted in both urban and rural areas. The site observation and survey had been put to use in two metropolitan areas' urbanization observation and investigation. On the other hand, the urban and rural areas' urbanization observation and investigation had been carried out on the trip between the two cities. The observation, investigation and analysis of urban and regional planning associated with them are made in the same time.

- Land utilization and landscape architecture: The main types of land development are different between urban and rural areas. The industrialized land, residential area, open space including parks, streets, and plazas are the major types of land utilization in urban areas. On the contrary, cropland is the major type of land utilization in rural areas. The same strategy are adopted: the site observation and investigation related to the urban land utilization had been put to use in two cities and observation of rural land utilization had been carried out on the trip between the two cities.

- Cultural landscape: As a key concept accepted by experts from various areas to understand humanshaped environments[6], cultural landscape includes abundant contents such as traditional buildings, groups of workshops, water uses including reservoirs, waterways, and harbors, transportation and communication systems including roads, avenues, and plazas. Taking traditional buildings for example, the summary including history, buildings and layout were shared indoor at the first stage of fieldwork. After that, the external environment, interior structure, and function classification were scrutinized carefully and experienced in-depth at the second stage.

- Population mobility and globalization: As the costs of mobility have fallen, the separation between places has shrunk. This is a process known as time-space convergence, which has contributed greatly to globalization[7]. The observation and investigation of population mobility and globalization were carried out by informal interviews, direct observation, and questionnaire survey in fieldwork destinations.

\section{The integration of multi-technology}

With the advent of the critical paradigm shift, the integration of open-ended interviews, documentary work, oral histories, participatory action research have all taken positions of prominence in human geography fieldwork[8]. In the exploration and detailed description of certain area or region, the topics of human geography fieldwork vary from global migration, attachment to the place, to consumer behavior in the shopping mall or traditional market. "The field can be a piece of land or a specific place with defined boundaries but it can also be something as amorphous as cyberspace." Fieldwork is a complex process that involves both the fieldworkers and the field, among which fieldworkers, i.e. students, and fieldwork method are the two predominant driving factors. The integration of multi-technology can stimulate students' interest better, which improve the fieldwork efficiency greatly.

- Pay attention to the selecting of reasonable methods: The methodology of fieldwork is capacious and eclectic, encompassing quantitative and qualitative strategies of data collection. It includes interviews, survey research, broad observational studies, casual conversation, environmental autobiographies, oral histories, mapping and measurement techniques[9]. Taking educational aims, time available, distance, student readiness, and availability of localities and resources into account, two sets of methods were designed. The first group included in-depth interview, oral histories, environmental autobiographies, mapping and measurement techniques, which were used in the first stage of fieldwork in Quanzhou. The second group included survey research, broad observational studies, and casual conversation, which were used in the second stage of fieldwork in Shanghai. To obtain detailed, deep, up-close, emic understanding of human geography research method, data collection strategies include both detailed observation and interview were conducted based on the theme of users' preferences and perceptions to landscape architecture in Quanzhou. The physical setting of specified urban park was the 
subject of careful examination. At the same time, the preferences and perceptions from an emic perspective of urban residents was the subject of unstructured open-ended interviews.

- Take full advantage of digital equipments possessed by students: The Internet and digital equipments have become ubiquitous in our daily lives. Cyberspace and digital equipments can enrich the learning space and enhance the student learning experience. All of the students in our campus possess multimedia equipments such as smartphones, laptops, and digital cameras. The employment of these equipments as data capture devices in the field can enhance the students learning efficiency[10]. During the whole fieldwork course, the advisors encouraged the utilization of the equipments. The itinerary choice of tour of observation aided by the laptops and online maps were recommended. Arriving at the destinations guided by smartphones equipped with orientation application were parts of fieldwork study tasks. The photographs taken by smartphones or digital cameras were needed in the summation presentation.

- The choice of fieldwork destination: The outdoor environment has much to offer to the expansion of geographical knowledge among student cohorts, but care is required to maximize its potential[11]. Two cities, i.e. Shanghai and Quanzhou, had been selected as the fieldwork destinations. Shanghai, the biggest city in China, is an excellent destination for a human geography fieldwork because the economic and cultural landscape is rich in diversity that can be readily observed by students. Quanzhou, the city where the campus is located, is another excellent destination for a human geography fieldwork because it is easier for the lecturers to research the location and integrate the fieldwork into an existing human geography course, and it is simpler for students to participate in the fieldwork outside of the academic day if needed.

- Give a full play to a variety of teaching modes: The multiple teaching mode is of very important practical value in improving the efficiency of the fieldwork. In order to utilize the time of fieldwork adequately and improve its pertinence, different teaching modes including impartation, discussion, discovery and other modes were employed under different situation. All kinds of activities were carried out under the lecturers' and students' participation and cooperation in order to complete the specific fieldwork goals. At times students work in groups of four to five, investigating special issue in appointed area. Occasionally some matters were brought up for discussion. Now and then special presentations were given by students or lecturers.

- Make the most of GIS: Geographic Information Systems(GIS) has emerged as one of the most important and widely used software for the social scientists including human geographers in last two decades[12]. The innovations in GIS offer myriad opportunities for human geographers to represent and visualize human geographic process in new and innovative ways and to integrate them with ongoing environmental and economic change. In order to improve the efficiency of the fieldwork, GIS is used to input, store, retrieve, manipulate, analyse and output geographically referenced date or geospatial data at all stages. At the first stage, it is difficult to introduce the fieldwork destination overall efficiently without the map display of GIS. Aided by GPS, GIS can process information collected during the outdoor fieldwork effectively. At the last presentation, it is important to demonstrate the discoveries which used GIS as the essential analytic and expressive tool.

\section{Extension of the fieldwork}

Fieldwork is perceived by lecturers and students alike as an enjoyable, valuable learning experience outside in the real world[11]. A human geography field trip usually lasts 2 weeks, which begins with preparation in the classroom and ends in some form of follow-up activities such as representations or posters. The preparation and follow-up stages involve library research and sometimes the use of large databanks of information in the form of a GIS. To make the most of the fieldwork, some improvement strategies in the classroom were designed by the lecturers with the assistance of colleagues. Setting more focus on the fieldwork during theoretical constructs in classroom teaching is the substantial part of these strategies. The following actions were taken frequently. Taking photographs and videos related to the fieldwork as examples in the discussion of some phenomena, theories and methods related before the fieldwork. Choosing topics related to the fieldwork as the possible discussion topics after the fieldwork. Students are encouraged to develop the inspiration from fieldwork into the topics of their dissertation.

\section{CONCLUSION AND DisCUSSION}

Fieldwork, unlike other indoor curricula, could engage students and allow them to acquire better mastery of human geographical skills such as identification and interpretation of human geographical information, and map reading. By fieldwork, students are more likely to understand and remember human geographical concepts and theories that they had obtained better than through other approaches. To what extent the fieldwork fulfills the requirements depends on many factors such as fund support, physical and mental condition of students, and validity and practicality of fieldwork itinerary. Through the various teaching modes reform discussed above, the human geography fieldwork achieved expected effect from the perspective of students and lecturers. Evidence of this effect is taken from interview responses before and after the fieldwork teaching.

Two main factors accounted for these positive consequences of the fieldwork experience. First, designing the fieldtrip with utmost care such as the choice of destination and the typical and representative domains laid a solid foundation for the fieldwork achievement. And the extension solidified the foundation better. 
Second, the integration of multi-technology ensured the high levels of efficiency in the fieldwork tasks fulfillment. The method selected in different stage, the application of digital equipments, the proper destination choice, and the utilization of different teaching modes and GIS made it possible to finish the whole fieldwork content within limited time.

Some limitations in this study should be considered. First, a more in-depth analysis on the combination of multi-methods might provide additional explanations to the students' acquisition of knowledge, improvement of skill, and adjustment of value orientation. Second, to get a more profound view of the impact of fieldwork on students' fundamental concepts of relationships between human society and nature, it is necessary to collect and analyze data about the process of geographical thinking based on quasi-experimental design. Such data can help to better understand the students' mental features and the regulations of their cognitive development.

\section{SUMMARY}

The study has demonstrated the importance of fieldwork in human geography in the curriculum of geography. And improvements of the pedagogy of fieldwork in human geography are discussed. However, there is still much room left for future studies. Future studies will explore the virtual field trip, the arrangement of international fieldwork, the integration of human geography fieldwork and physical geography fieldwork.

\section{REFERENCES}

[1] D. Gregory, T, Johnston, G. Pratt, M. Watts, and S. Whatmore, Human geography, The Dictionary of Human Geography(5th Edition), pp. 350354, 2008.

[2] I. Fuller, S. Edmondson, D. France, D. Higgitt, and I. Ratinen, International perspectives on the effectiveness of geography fieldwork for learning, Journal of Geography in Higher Education, vol. 30, pp. 89101, 2006.

[3] S. Andelkovic, V. Dedjanski and B. Pejic, Pedagogical benefits of fieldwork of the students at the Faculty of Geography in the light of the Bologna Process, Journal of Geography in Higher Education, vol. 42, pp. 110-125, 2018.

[4] J. DeW itt and M. Storksdieck, A short review of school field trips: key findings from the past and implications for the future, Visitor Studies, vol. 11, pp. 181-197, 2008.

[5] B. Warf, Urbanization, Encyclopedia of human geography, pp. 530-533, 2006.

[6] B. Warf, Cultural landscape, Encyclopedia of human geography, pp. 7578, 2006.

[7] D. Gregory, T. Johnston, G. Pratt, M. Watts, and S. Whatmore, Mobility, The Dictionary of Human Geography(5th Edition), pp. 467-468, 2008.

[8] C. Pope, and W. Price, Fieldwork in human geography, International Encyclopedia of Geography: People, the Earth, Environment and Technology, pp. 1-9, 2016.

[9] D. Gregory, T. Johnston, G. Pratt, M. Watts, and S. Whatmore, Fieldwork, The Dictionary of Human Geography(5th Edition), pp. 251252, 2008.

[10] K. E. Welsh, A. L. Mauchline, V. Powell, D. France, J. R. Park and W. B. Whalley, Student perceptions of iPads as mobile learning devices for fieldwork, Journal of Geography in Higher Education, vol. 39, pp. 450469, 2015.

[11] I. C. Fuller, Taking students outdoors to learn in high places, Area, vol. 44, pp. 7-13, 2012.

[12] B. M. Alam, Application of geographic information systems, pp. IX-X, 2012. 